\title{
Piolhos, Poesia e Política ${ }^{1}$
}

\author{
Daniel Mundurucu ${ }^{2}$ \\ Núcleo de Cultura Indígena
}

\begin{abstract}
Solicitado a desenvolver uma reflexão sobre as questões ambientais contemporâneas, o líder indígena Daniel Mundurucu discorre sobre os significados da expressão "relações harmônicas do homem com a natureza" à luz da tradição cultural indígena culminando por fortalecer a idéia de existência de aspectos universais no entendimento das questões ambientais sugerindo que, quando as mesmas são enfocadas sob referenciais humanísticos descritos com base na história dos diferentes grupos humanos, emerge a visão da teia da vida como bem-comum a ser preservado.
\end{abstract}

Descritores: Natureza. Cultura indígena. Conhecimento. Grupos socioculturais. Fatores ecológicos.

( audação) Na tradição do povo Mundurucu, quando a gente chega num ( $N_{\text {lugar que não é a casa da gente, a gente tem que fazer uma saudação }}$ para as pessoas, e a saudação que eu fiz para vocês diz assim: boa noite a todos os amigos aqui presentes; eu espero que esse encontro seja tão bom para vocês como ele vai ser para mim. E eu queria agradecer mesmo pelo fato de ter um representante indígena num seminário, um simpósio de relevância tão grande, e dizer que eu estou aqui em um papel meio confuso, porque eu vim representando Ailton Krenak, que é o presidente do Núcleo de Cultura Indígena e que não pôde estar aqui hoje para conversar com vocês. É meio embaraçoso porque o Ailton tira poesia de pedra e eu não sei

1 Transcrição: Maria Eugênia Blanques de Gusmão.

2 Líder indígena do Povo Mundurucu, Pará, doutor em Filosofia e especialista em Antropologia Social. 
fazer isso. Mas eu gostaria de dizer algumas palavras, colocando um pouco a nossa posição, a posição dos povos indígenas diante desse tema e dizer que eu sou de um povo lá da Amazônia, que é o povo Mundurucu, que é um povo que já tem um contato com a população brasileira há mais de 200 anos, um povo que tem passado por muitas transformações, e que tem procurado se adaptar aos novos tempos nunca deixando de lado a sua própria tradição. Meu povo tinha um hábito cultural, que também foi sendo deixado de lado ao longo desse tempo, que é o hábito de cortar a cabeça dos inimigos de guerra. Por isso não mexam comigo! Cabeças rolarão. A gente está ali no estado do Pará todo esse tempo buscando nos manter vivos e nos manter atuantes dentro do cenário da própria Amazônia.

Eu queria, então, só desenvolver duas idéias como ponto de reflexão, lembrando até o conhecimento tradicional, um conhecimento dos povos indígenas do mundo inteiro, que é idéia de que nós não somos donos da teia da vida, somos apenas um de seus fios, e que a gente não tem posse sobre o ambiente, a gente tem parceria, a gente tem que viver como parceiros e não como donos, até porque a terra nos é dada, a natureza nos é dada, a vida nos é dada como um brinde, como um presente, e a gente devia tratar isso como um presente que a gente tem que cuidar direito. Portanto, esse presente é que precisa ser bem cuidado.

Eu lembro que numa passagem do grande prof. Darci Ribeiro, ele me contava um caso que aconteceu numa aldeia dos índios Gavião lá do Pará. Ele estava em uma situação um pouco tristonha, meio solitária. Ele era ainda moço, um pesquisador novato de área, e ele estava lá meio triste, cabisbaixo, e ao lado dele tinha um casal. A mulher estava catando piolho na cabeça do marido, deitado no colo dela e ela catava piolho na cabeça dele. A mulher, sensível como são as mulheres, perguntou ao Darci o que estava acontecendo, porque ele estava tão triste daquele jeito, e ele falou que estava triste porque estava com saudade de Berta Ribeiro, esposa, e que estava ali sozinho, muito solitário, e que não conseguia esquecer, então estava assim, meio jururu. E aí a mulher ficou olhando para ele e disse assim: Então eu vou te dar um presente para você levar para Berta, para quando você chegar lá, Berta ter o que fazer em você. Pegou dois piolhos da cabeça do marido e 
jogou na cabeça de Darci e disse para ele: - Olha, isso daí vai fazer com que ela deite você no colo dela e vai ficar um tempão cuidando de você.

Os seres da natureza são assim; servem para unir as pessoas, eles não estão ali para estragar a união, não estão ali para destruir, eles servem para unir. E, às vezes, a gente esquece disso. E a gente costuma tratar das coisas vivas da natureza como se fossem coisas que estão atrapalhando a nossa vida e, na verdade, elas estão ali é para unir a gente. Uma segunda coisa que eu gostaria de dizer para vocês é que meu avô, ele falava com os seres da natureza. Ele sentava contando histórias para gente e dizia que muitas vezes ele conversava com o rio, com as árvores, com os animais, e perguntava para esses seres o que ele devia fazer, como ele devia fazer o que tinha que ser feito. E esses seres da natureza, amigos que são sempre, contavam para ele o que ele precisava. E ele nos contava isso com muita simplicidade, simplicidade que os sábios têm, e contava isso dizendo que disso dependeria também o nosso futuro, aquilo que nós seremos mais tarde. E ele dizia que se a gente quebrar esse elo com os seres da terra, a gente vai quebrar a harmonia, e é possível que o céu venha a cair em cima da gente, é possível que a terra despenque no vazio. E ele afirmava assim, sobre os velhos pagés que ficam chacoalhando o seu maracá, o seu chocalho, para curar as pessoas, ele ficava falando dos jovens que dançam muito tempo batendo os pés no chão para manter a terra equilibrada. E ele contava que os rios não paravam diante dos obstáculos para poder manter a harmonia das águas. E ele contava do fogo, dizendo que era preciso manter o fogo sempre aceso. Tanto esse fogo externo que nos aquece, quanto o fogo interno que gera esperança, que cria esperança. Essas coisas muito simples, ditas por um selvagem, é que no nosso jeito de entender o universo tem mantido o céu suspenso, tem mantido a terra viva. E é esse céu suspenso que nós queremos manter, não importa o nome que se dê a isso. Psicologia, antropologia, filosofia, nomes, posses. A gente quer é que as pessoas se harmonizem com a própria natureza e que entendam que cada um de nós segura a ponta do fio que forma essa teia, essa teia invisível que é formada no infinito e pelo infinito das pessoas que estão espalhadas por esse planeta todo. Era isso que eu queria dizer para vocês. Obrigado. 


\title{
Daniel Mundurucu
}

Mundurucu, D. (2005). Lice, poetry and politics. Psicologia USP, 16(1/2), 35-38.

\begin{abstract}
Requested to develop a reflection on contemporary environmental issues, the Indian leader Daniel Mundurucu discusses the meanings of the expression "harmonious relations between man and nature" in light of the Indian cultural tradition. He strengthens the idea of the existence of universal aspects in the understanding of environmental issues, suggesting that, when they are analyzed according to humanistic frameworks described through the history of different human groups, the view of the web of life as the common good to be preserved emerges.
\end{abstract}

Index terms: Nature. Indigenous culture. Knowledge. Sociocultural groups. Ecological factors.

Mundurucu, D. (2005). Poux, poesie et politique. Psicologia USP, 16(1/2), 35-38.

Résumé: En vue de développer une réflexion sur les questions contemporaines d'environnement, le chef indigène Daniel Mundurucu expose les significations de l'expression "relations harmonieuses de l'homme avec la nature" à la lumière de la tradition culturelle indigène. L'exposé culmine par le renforcement de l'idée de l'existence d'aspects universels selon le concept des questions de l'environnement, suggérant que lorsque ces dernières sont envisagées sous l'optique des référentiels humanistes décrits sur la base de l'histoire des différents groupes humains, émerge une vision de la trame de la vie en tant que bien commun à préserver.

Mots-clés: Nature. Culture indigène. Connaissance. Groupes socioculturels. Aspects écologiques. 